\title{
Comprehension of printed sentences by children with reading disability
}

\author{
DONALD G. DOEHRING \\ McGill University, Montreal, Quebec, Canada H3G 1 A8
}

\begin{abstract}
Sentence comprehension was studied in children with different types of reading disability in relation to their other reading skills. For the types of reading problems assessed, sentence comprehension was at the same level of proficiency, relative to normal readers, as was oral word reading. Significantly higher correlations were observed between sentence comprehension and four tests involving oral word reading than between sentence comprehension and almost all of the remaining 27 tests. Results are discussed with regard to mechanisms underlying sentence comprehension in normal readers and children with reading disability.
\end{abstract}

Several types of reading disability have been identified, including those associated with particular difficulty in visual perception, auditory perception, visual-auditory association, and various language skills (Boder, 1973; Kinsbourne \& Warrington, 1963; Mattis, French, \& Rapin, 1975). Reading comprehension is deficient in all of these types of reading disability, but the relative impairment may vary, and some reading problems may be largely restricted to comprehension (Cromer, 1970; Huttenlocher \& Huttenlocher, 1973). An estimate of reading comprehension in children with different types of reading disability should provide useful information regarding the degree to which comprehension is affected by selective deficits of reading acquisition. In the present report, the sentence comprehension of children with different types of reading disability was assessed in relation to their other reading skills.

\section{METHOD}

The two samples of children tested included 31 boys and 3 girls, aged 8 to 17 years, from a summer program for children whose primary problem was in reading, and 22 boys and 9 girls, aged 8 to 12 years, whose reading problems were associated with learning disorders, language disorders, and mental retardation. All had been given 31 tests which required rapid and accurate visual scanning, visual matching, auditory-visual matching, or oral reading of numbers, letters, syllables, and words (Doehring, 1976); the Q-technique of factor analysis had been

The writer wishes to thank Frank Greene, Director of the McGill University Reading Center, M. Sam Rabinovitch, Director of the McGill-Montreal Children's Hospital Learning Center, the Protestant School Board of Greater Montreal, and the staffs of Herbert Symonds and Willingdon Schools for their cooperation. Thanks are also extended to Irene $\mathbf{M}$. Hoshko for assistance in testing and statistical analysis, and to Bonnie Bryans for comments on the manuscript. This research was supported by Grants 604-7-858 from the Canadian Department of National Welfare and MA-1652 from the Medical Research Council of Canada. Address reprint requests to D. Doehring, Beatty Hall, 1266 Pine Avenue West, Montreal H3G 1A8, Quebec, Canada. used to classify the children into subgroups on the basis of common patterns of test performance (Doehring \& Hoshko, in press). The most interpretable factor solutions classified 31 of the 34 children in the reading problem sample and 26 of the 31 children in the mixed problem sample into three distinct profiles of deficit within each sample. Two of the profiles were common to both samples, one characterized by very slow auditory-visual letter association and the other characterized by severe deficits in auditory-visual syllable matching. The third profile in the reading problem sample involved marked difficulty in oral word and syllable reading, whereas the remaining profile in the mixed problem sample involved poor visual matching.

A test of sentence comprehension was administered to all children at the same time as the other tests. The results, which were not analyzed as part of the study of reading profiles, are presented here. The test involved silent reading of a simple sentence with a missing word, followed by spoken production of the missing word as quickly as possible. The 16 printed test sentences are shown in Table 1 . Highly predictable nouns had been omitted from eight sentences and highly predictable function words had been omitted from the remainder.

\section{RESULTS}

Results for the sentence comprehension test were scored in terms of percentiles derived from 100 normal

Table 1

Test Sentences in Order of Presentation, With Correct Responses in Parentheses

(Once) upon a time, a princess lived in a magic land.

Wash your face (and) hands before supper.

These apples are too green (to) eat.

I worked hard (all, to, every, that, one, each) day.

The (dog, cat, boy, man) chased the cat up the tree.

Mother asked me to buy a (loaf, bag) of bread at the store.

The story had a happy (ending, end).

John's pen ran out of (ink, food).

A wind (from, in, of, to) the north froze the pond.

I dropped my fork (on, onto, upon) the floor.

No, dinner's not ready (yet, now, dear).

They lived happily ever (after).

I put (salt, gravy) and pepper on my meat.

Blow out the (candles) on your birthday cake.

Our hen laid an (egg).

Look both ways before you cross the (street, road). 
readers between the 1 st and 10th grades, using a rationale that had been devised for percentile scaling of the other 31 reading tests (Doehring \& Hoshko, in press). Children who made seven or fewer errors on the 16 sentences were assigned percentiles on the basis of median response latency, with errors scored as infinitely long latencies; children making eight or more errors were assigned percentiles on the basis of total errors.

As expected, the two samples of children with reading problems performed the sentence comprehension task very poorly relative to normal readers. The accuracy criterion of seven or fewer errors was not met by 15 of the 34 children in the reading problem sample, of whom 3 made no correct responses, nor by 19 of the 31 children with mixed problems, of whom 9 made no correct responses. Where the accuracy criterion had been met, response latency was invariably slower than that for normal readers of the same age, usually by a factor of more than 3 to 1 .

Relative proficiency of sentence comprehension skill was estimated for each child by comparing the comprehension percentile with the previously determined percentiles for the other 31 tests. Sentence comprehension was at the same percentile level as four tests involving the oral reading of words for 28 of the 34 children in the reading problem sample and for 29 of the 31 children in the sample with mixed problems. For these children, percentile levels on the remaining tests differed from those for sentence comprehension to the extent that oral word-reading skills differed from other reading skills for the particular profile of deficit into which the child had been statistically classified. The eight children whose comprehension percentiles differed from their oral word-reading percentiles did not fall into any particular reading disability subgroup, two having profiles characterized by poor oral word and syllable reading, two with the profile involving difficulty in rapid auditory-visual letter associations, one with the profile involving difficulty in auditory-visual syllable matching, and the remaining two children among those unclassified by the Q-technique (Doehring \& Hoshko, in press).

Correlations between the comprehension test and the other 31 tests (all having adequately distributed scores) were remarkably similar for the two samples of children with reading problems. Correlations with the four oral word-reading tests, which included oral reading of unrelated common words, of 2nd- and 7th-order approximations to sentences, and of simple sentences (Doehring, 1976) were $.79, .81, .81$, and .83 , respectively, for the reading problem sample and $.83, .83, .81$, and .80 for the sample with mixed problems. These correlations did not differ significantly (Ferguson, 1971) among themselves within either sample, and were significantly higher $(p<.05)$ than correlations for almost all of the remaining 27 tests, the only exceptions being a correlation of .68 with oral reading of uppercase letters for the reading problem sample and correlations of .70 with oral nonsense syllable reading and .68 with visual scanning for nonsense syllables for the mixed problem sample. The correlations between the sentence comprehension test and the oral word-reading tests could not have been entirely attributable to the common task requirements of word retrieval and articulation, since all but one of 12 correlations involving tests which required letter, picture, or color naming (Doehring, 1976) were significantly lower than the correlations with oral word reading.

\section{DISCUSSION}

Relative proficiency in sentence comprehension tended to be the same as that for oral word reading in both samples of children with reading problems, regardless of the reading problem subgroup into which a child had been classified. Reading comprehension was probably limited to about the same extent in each subgroup by oral word-reading proficiency. The selectively high correlations between sentence comprehension and oral word reading provided an additional indication that children in the present samples were restricted to word-by-word decoding strategies in arriving at the meaning of sentences, as compared with higher level strategies used by normal readers in the same age range (Doehring \& Hoshko, 1977).

For the types of reading problems represented in the present samples, then, different patterns of reading skill impairment can lead to the same practical limitation on the extraction of meaning from printed sentences. Although theoretically possible, there may be no subtype of developmental reading disability where comprehension skills exceed oral word-reading skills, as sometimes occurs in aphasic adults (Goodglass \& Kaplan, 1972). More precise information about the relation between oral word-reading and sentence comprehension skills might be obtained in further research by having the child read the sentence aloud as rapidly as possible after attempting to supply the missing word.

\section{REFERENCES}

Boder, M. D. Developmental dyslexia: A diagnostic approach based on three atypical reading-spelling patterns. Developmental Medicine and Child Neurology, 1973, 15. 663-687.

Cromer, W. The difference model: A new explanation for some reading difficulties. Journal of Educational Psychology, 1970, 61, 471-483.

Doenring, D. G. Acquisition of rapid reading responses. Monographs of the Society for Research in Child Development, 1976, 41, No. 165.

Doenring, D. G., \& Hoshko, I. M. Classification of reading problems by the Q-technique of factor analysis. Cortex, in press.

Doenring. D. G., \& Hoshкo, I. M. A developmental study of the speed of comprehension of printed sentences. Bulletin of the Psychonomic Society, 1977, 9. 311-313.

FERguson, G. A. Statistical analysis in psychology and education [3rd ed.]. New York: McGraw-Hill. 1971.

Goodglass, H., \& KAPLAN, E. The assessment of aphasia and related disorders. Philadelphia: Lea \& Feibeger, 1972. 
Huttenlocher, P. R., \& Huttenlocher, J. A study of children with hyperlexia. Neurology, 1973, 23, 1107-1116.

Kinsbourne, M., \& Warrington, E. K. Developmental factors in reading and writing backwardness. British Journal of Psychology, 1963, 54, 145-156.

Mattis, S., French, J. H., \& Rapin, I. Dyslexia in children and adults: Three independent neurological syndromes. Developmental Medicine and Child Neurology, 1975, 17, 150-163.

(Received for publication June 22, 1977.) 